\section{The future of care for frail elderly patients: our first steps towards progress}

\author{
Riaz Dharamshi
}

Frail elderly patients in the UK need a form of care that we are not used to delivering. For these patients, healthcare is not about surviving and recovering from illness; it is about living with it, managing it and seeking a good quality of life in spite of it. These are patients with multiple medical conditions for whom managing the impact and symptoms of their problems is a daily experience. They often have impaired cognition and are easily disorientated. Their medical needs ebb and flow, but never go away entirely. They often have limited mobility and find it difficult to travel.

What these patients need is routine oversight and expert multidisciplinary input into their ongoing problems. They need it to be easy to access, expert and delivered close to their own homes. They need rapidly accessible support on their bad days, expert assessment of their deterioration and time given over to planning what to do in the future when their situation inevitably deteriorates. What they are given, however, is a fragmented array of interventions and services that do not reflect their needs; often, consultant expertise is only available if they travel to the clinic or the hospital. In the absence of advance care planning they are admitted to hospital as emergencies for the want of appropriate community services that could meet their needs. Community-based care is offered by narrowly defined teams, which can mean that patients experience multiple visits from carers and healthcare professionals without one team taking an overall lead in their care needs. I once met a patient who, during the space of 1 day was visited by her carers (three times), the district nurse, the palliative care team, the tissue viability nurse and her GP. In her final days of life her front door became the meeting place for the local community health and social services, and she felt invaded. This case is not unusual: for these patients, whenever a new need is identified, they are directed back to their GP for

Correspondence to Dr Riaz Dharamshi, Department of Community Geriatrics, Dorset Healthcare University NHS Foundation Trust, Dorset, UK; riazdharamshi@nhs.net another referral to another team to be made.

It is no secret that the greatest challenge facing the NHS is the challenge of meeting the needs of an ageing population-a task heightened by recent financial constraints. Frail elderly patients do present an enormous test to the NHS, but so far the response has been inconsistent and stumbling. There is huge variation in the services available to these patients, which highlights the potential for improvement. A study by the King's Fund $^{1}$ found significant variations in admission rates for people aged over 65 across the country, with the best performance in areas with integrated services and with higher levels of people in this age group. The implication is that areas with a larger number of older people have focused on services to meet their needs.

But we need to dig deeper: 'Integration delivers better outcomes' is the headline, but it is not the whole story. The key to understanding success is to understand what was integrated. This is the rub of the integration narrative-one that has fallen short of expectations because of overattention on the process of integration rather than the actual services being integrated. It has perhaps always been selfevident that services need to be in tune with each other, but too many people have repeated this observation and too few have offered useful advice about how it is actually done. Integration has therefore suffered from something of a framing problem: it has been treated as a goal whereas, in truth, it is something that results naturally from well-designed, wellimplemented services. Integration is one of the diagnostic features of an effective service, but it is not the solution to a specific healthcare problem. Frail elderly patients do not just need integrated services. They need services organised around them that solve the problems highlighted above. Integration taken by itself means 'joining up' services, but the real solution is broader. It is about offering the right care, in the right place, at the right time. Too often, at present, the care offered to frail elderly patients is limited by the structures of the system and not by their needs. There is no point in coordinating services that are inherently ill-suited; first they need to be adapted and then they need to be coordinated.

The Buurtzorg ${ }^{2}$ home care service in Holland has recognised this problem and addressed it. Their locality-based teams of qualified nurses establish what patients need from them and establish among themselves how this need can be met. These teams are autonomous, empowered and responsible for meeting all the needs of their patients, not just some of them. Patients deal with one small team of people, and that team is charged with problem-solving on behalf of the patients. Their results are impressive: fewer care hours required, costs are contained, and both staff and patient satisfaction is high. They have achieved the goal of integration, not by joining up services but by thinking about what patients need and changing the way that they work in order to deliver it.

The challenge for us all, therefore, is to examine the way we deliver care and establish how far our practices have deviated away from the needs of the people we serve. The Buurtzorg model (box 1) works because the team members understand that they must work across broad professional boundaries but, in doing so, they are supported by the wide professional skills of their colleagues and supplied with the systems and support that they need. This includes the right IT systems and management support, but also includes the creation of an environment in which they are personally and professionally responsible for how they deliver care. They create the time and space to review regularly their work as a team.

The case for change here in the UK and some of the approaches we need to consider have been put forward by The Royal College of Physicians' Future Hospital

\section{Box 1 The Buurtzorg method ${ }^{3}$}

- Component 1: Assess client's needs holistically

- Component 2: Draft an individual care plan, based on client's needs

- Component 3: Identify and include formal carers

- Component 4: Deliver the care the client needs

- Component 5: Support the client in his/her social roles

- Component 6: Promote self-care and independence 
Commission (FHC). ${ }^{4}$ It argues that services are variable, inconsistent and do not meet the needs of our ageing population. The FHC proposes a number of solutions, including the suggestion that consultants should consider community-based working as part of their routine and should play a central role in service development. Doctors have a significant role to play in creating the changes in practice.

We cannot just wait for structural and organisational change or-for that matter - for the future. For the current elderly population, that future is now. All healthcare professionals have a role to play in providing better services for patients, from their willingness to adopt practices to sharing their ideas and to committing their time to service review. However, the creation of the landscape in which this is possible requires leadership. The role for doctors is more than just modelling behaviours; it also involves embracing their role in service development and stepping outside their usual practice environments. It involves creating team environments which embrace shared decision-making and outlining what 'better' looks like. The challenge of integrating services will only be met if all healthcare professionals are open to the idea of examining how they make their expertise available to the patients. Change is needed from everyone, or nothing will really happen. As Jennifer Dixon $^{5}$ points out, it is the people who deliver healthcare that will change the system for the good by creating positive change environments and, importantly, by listening to the patients.

Structural, funding and organisational change becomes feasible if teams can demonstrate what is possible. There are a great many improvements that can be made before long-term and ambitious change strategies are chosen, but improvement is only possible if all healthcare professionals recognise the potential, listen to their patients and work in organisations that support and encourage them. The influence of doctors in creating the right culture cannot be understated: this intelligent articulate workforce has the potential to outline vision to their teams and demonstrate the need and nature of support required to make success possible.

Progress is not achieved through steering groups or committees. It is delivered by well-supported multidisciplinary teams that are backed up by management structures that ask themselves just three questions: 'What is this team doing well?', 'What issues is this team struggling with?' and 'What help does this team need from us?'
Competing interests None.

Provenance and peer review Commissioned; externally peer reviewed.

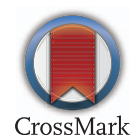

To cite Dharamshi R. Postgrad Med J 2014;90:427-428.

Received 13 June 2014 Accepted 24 June 2014

Published Online First 4 July 2014

Postgrad Med J 2014;90:427-428.

doi:10.1136/postgradmedj-2014-132843

\section{REFERENCES}

1 Imison C, Thompson J, Poteliakhoff E. Older people and emergency bed use. London: King's Fund, 2012. http://www.kingsfund.org.uk/publications/older-peopleand-emergency-bed-use (accessed 11 Jun 2014).

2 Monsen KA, de Blok J. Buurtzorg: nurse-led community care. Creat Nurs 2013;19:122-7.

3 Huijbers P. Care in the neighbourhood: better home care at reduced cost. http://interlinks.euro.centre.org/ model/example/

NeighbourhoodCareBetterHomeCareAtReducedCost (accessed 11 Jun 2014).

4 The Future Hospital Commission. Future hospital: caring for medical patients. The Royal College of Physicians, 2013. https://www.rcplondon.ac.uk/ projects/future-hospital-commission (accessed 11 Jun, 2014).

5 Dixon J. Beyond the edge: the future hospital. Future Hosp J 2014;1:10-12. 